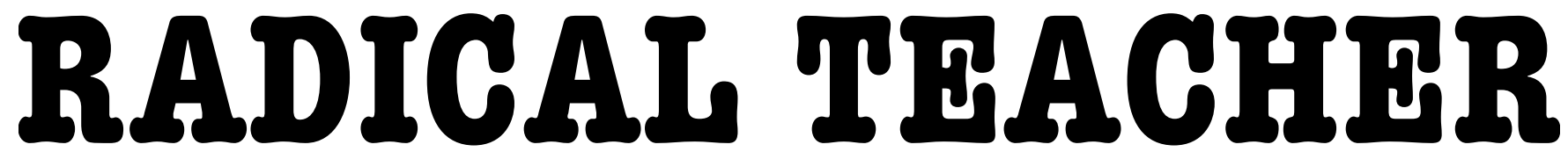

A SOCIALIST, FEMINIST, AND ANTI-RACIST JOURNAL ON THE THEORY AND PRACTICE OF TEACHING

\title{
One or Two Things I Think I Know for Sure about 1968-2018: The Movement, the MLA, and the Current Moment
}

\author{
by Frances Smith Foster
}

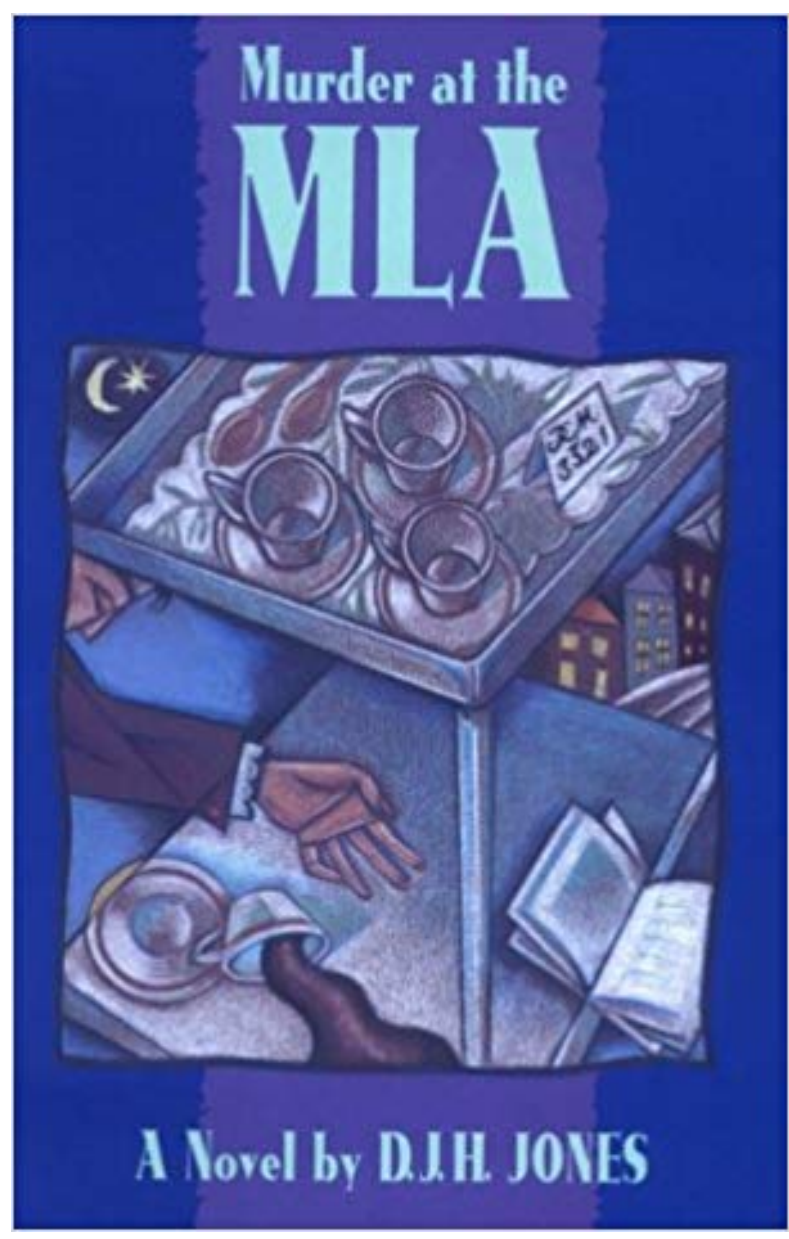

D. J. H. JONES. MURDER AT THE MLA. COVER BY LOUISE OFARRELL, UNIVERSITY OF GEORGIA PRESS, 1993. MLA ARCHIVES, NEW YORK. 
I am an accidental academic activist of the Sankofa persuasion. Sankofa is, as many of you know, a belief of West African origins -- that one must go back and retrieve from the past that which is useful for surviving the present and founding a better future. It is sometimes represented by a heart- shaped image, but I prefer the bird standing feet forward, looking back and holding an egg in its beak. Having taken a Western Civics class, I see similarities to the Roman god Janus. Having studied American Literature, I hear echoes of Faulkner's Requiem for a Nun: "The past is never dead. It's not even past." But while similar, Sankofa is its own distinct concept, a concept forged in African culture and most apt for my experiences as an African American. I became a teacher because my family and my community inculcated a strong sense in me that education is power and that believing a lie doesn't make it the truth. I practice what Toni Morrison calls "rememory" and I believe Professor Nell Painter's statement that "What we can see depends heavily on what our culture has trained us to look for." All this to say that I share much of what my colleagues describe but my remarks are eccentric, eclectic, and mixed with a lot of my lived experiences.

First of all, I was not at the 1968 convention. Nor, for that matter, were many other women or men of color. So I had to do a little research for context and my conclusion is that had I been at MLA in 1968, I probably would not have known about the rebellion we are commemorating now. I strongly suspect that experience would have been like Houston Baker's when he ventured to his first MLA that year. As a Victorianist (I aspired to be a Miltonist), Baker was enthralled by the learned lectures read with authority by the luminaries of his field. However, during his two and a half days in attendance, Baker says he saw "only one other person of color" and that individual physically distanced himself by sitting on the opposite side of the room. Houston Baker roamed the conference halls but was entirely unaware of what Paul Lauter characterizes as the "alternative convention" and "its radically disruptive effect on the normal practice of Modern Language Association business." As Houston Baker reports, "in truth, the full and distressing import of that early MLA experience did not come to me from the profession at large or from a left-based insurgency within it. No, the excessive whiteness, smug complacency, racial insensitivity, and black mutual avoidance evident at the 1968 convention were elucidated for me not by my colleagues but by my students" (PMLA 115.7). I, too, would have experienced (as I occasionally still do) certain other "unsettling" moments of what we now call microaggressive racism, though being a woman complicates the calculus of injuries intentional or not.

As Houston Baker reports, "in truth, the full and distressing import of that early MLA experience did not come to me from the profession at large or from a left-based insurgency within it. No, the excessive whiteness, smug complacency, racial insensitivity, and black mutual avoidance evident at the 1968 convention were elucidated for me not by my colleagues but by my students"

This is not to say the MLA had no members of color then. As a matter of fact, records show that the MLA has had African American and women members almost from its beginning. Dr. William Sanders Scarborough, a professor of
Greek whose passions were philology, pedagogy, and politics, joined in 1884. His wife, Professor Sarah C. B. Scarborough, joined soon after and records show them as active conference participants until 1897, when for reasons undocumented but imaginable, they kept their memberships but no longer attended.

A statement by the 1970 MLA president, Maynard Mack, complements Baker's experience of the 1968 MLA convention. Mack begins by saying, "Probably the best thing about the 1968 MLA Business meeting is that it is over." He deplores the "erratic forms" and "deplorable discourtesy," but Mack welcomes the conversation that has begun and acknowledges that among the MLA's many needs are revising the handling of resolutions to take "positions on substantive and not simply ceremonial issues in ways fair to both majority and minority opinion" and to elect officers "by poll of the entire membership."

I began my MLA sojourn nearly a decade later, unaware of the ruckus that preceded my attendance and led to changes such as establishing the Afro-American Discussion Group that made me a bit more comfortable. Much of what Mack had envisioned had come to pass. MLA not only had elected officers but also a Delegate Assembly and a multitude of groups and affiliated organizations to increase fairness to "both majority and minority opinion." What I remember most about my first experiences was feeling ignored or objectified by the radical left, the feminists, and virtually every conference attendee except the African Americans I encountered, most of whom, like me, were graduates of and token professors in predominantly white universities, self-taught in African American literature, and desperate for discussions about our fields. In the decade or so since Baker was in the Hilton but missed the brouhaha, the MLA I experienced had more women and people of color and scheduled enough sessions on multicultural literature to create conferences within a conference. Sadly, then as now, few white members attend sessions featuring scholarship by or about people of color.

What I remember most about
my first experiences was feeling
ignored or objectified by the radical
left, the feminists, and virtually
every conference attendee except
the African Americans I
encountered, most of whom, like
me, were graduates of and token
professors in predominantly white
universities, self-taught in African
American literature, and desperate
for discussions about our fields.

As Houston Baker reports, "in truth, the full and distressing import of that early MLA experience did not come to me from the profession at large or from a left-based insurgency within it. No, the excessive whiteness, smug complacency, racial insensitivity, and black mutual avoidance evident at the 1968 convention were elucidated for me not by my colleagues but by my students" 
In the 1990s, three critical problems dogged those of us whose color or contours were not pale and male. These problems are well articulated in Nellie Y. McKay's 1998 PMLA article "Naming the Problem That Led to the Question 'Who Shall Teach African American Literature?' . . . " According to McKay, while a handful of us were surviving in the academy and actually faring rather well in MLA, (1) there was a pipeline shortage of black graduate students, (2) talented white students were being steered away from focusing on African American literature, and (3) opportunistic white scholars with little or no training in the subject were given authority to teach, publish, and pontificate about African American literature

But to get back to the Sixties, consider Maynard Mack's conclusion that the 1968 disruption revealed "the profound mistrust that was there shown to divide us. It was not, apparently, a mistrust founded on personal knowledge or on the moral character and past performance of the persons mistrusted. It was something far more abstract and inhuman, feeding on slogans and clichés, applying not considered judgments but labels. . . I submit." Mack declares "that the first job for all of us now is to master our fears of each other and close ranks, opening in the Association and likewise in the profession all the avenues of communication that imaginations can invent."

Mack's statements then are disappointingly accurate now. As Paul Lauter, Richard Ohmann, and Louis Kampf wrote in the proposal for this session, "In one sense, we utterly failed [to achieve the goals of 1968]. . . But seen from an historical perspective . . . we succeeded beyond our wildest imaginings." My Sankofa faith leads me to end with a quote from a 1902 PMLA article called "Concerning the Unwritten History of the Modern Language Association of America":

Much has been accomplished in the brief history of this Association, but that much is the merest symbol of what remains to be done... 